\title{
Ti45Nb Alaşımının Aşınma Davranışına Anodizasyon Potansiyelinin Etkisi
}

\author{
The Effect of Anodization Potential on Wear Behaviour of Ti45Nb Alloy
}

\author{
Muharrem TAŞDEMIR $^{* 1, a}$, Fatih ŞENASLAN ${ }^{1, b}$, Ayhan ÇELİK ${ }^{2, c}$ \\ ${ }^{I}$ Gümüşhane Üniversitesi, Mühendislik ve Doğa Bilimleri Fakültesi, Makine Mühendisliği Bölümü, 29100, Gümüşhane \\ ${ }^{2}$ Atatürk Üniversitesi, Mühendislik Fakültesi, Makine Mühendisliği Bölümü, 25100, Erzurum
}

• Geliș tarihi/Received: 24.05.2019 • Düzeltilerek geliș tarihi/Received in revised form: 20.01.2020 • Kabul tarihi/Accepted: 11.02 .2020

\section{Öz}

Titanyum ve alaşımları düşük yoğunluk yüksek dayanım oranı, mükemmel biyouyumluluk ve iyi korozif özelliklerinden dolayı endüstriyel birçok alanda kullanılmaktadır. Fakat titanyum ve alaşımları zayıf yüzey özelliklerine sahiptir. Titanyum ve alaşımlarına aşınma direnci ve malzemenin kullanım süresini artırmak amacıyla çeşitli yüzey işlemleri uygulanır. $\mathrm{Bu}$ çalışmada, Ti45 $\mathrm{Nb}$ alaşımının yüzeyinde farklı anodizasyon şartları altında oksit film tabakası oluşturulmuştur. Titanyumun yüzeyinde oluşan oksit film kalınlığının ve sertliğinin kuru aşınma şartları altında etkisi araştırılmıştır. Numunelerin oksit film katmanının faz yapısı XRD, yapısal özellikleri ve kesit görüntüsü SEM ile incelenmiş̧tir. Ayrıca numunelerin yüzey sertliği ise mikro sertlik cihazıyla ölçülmüş̧ür. Elde edilen sonuçlar, Ti45Nb yüzeyinde anodizasyon potansiyelinin artmasıyla oksit film kalınlığının ve sertliğinin arttığı belirlenmiştir. Buna bağlı olarak anodize edilmiş Ti45Nb alaşımının aşınma dayanımının arttığı tespit edilmiştir. Ayrıca anodizasyon potansiyelinin artmasıyla malzemenin yüzey pürüzlülüğü ve porozitesi artmıştır.

Anahtar kelimeler: Anodizasyon, Aşınma, Niyobyum, Titanyum, Ti45Nb

\begin{abstract}
Titanium and its alloys are used in many industrial fields because of their low density-high strength ratio, excellent biocompatibility and good corrosion properties. Nevertheless, titanium and its alloys have poor surface properties. Titanium and its alloys are applied various surface treatments for increasing wear resistance and service life. In this study, the oxide layer was formed under different anodization conditions on the surface of Ti45Nb alloy. The effects of thickness and hardness of oxide layer was investigated under dry wear conditions. The $\mathrm{TiO}_{2}$ phase form of samples was obtained by XRD. Structural properties and cross-section view of samples examined with SEM. Also, the surface hardness of samples was measured by micro hardness. In conclusion, the thickness and hardness of oxide layer increased within increasing anodization potential on Ti45Nb surface. Accordingly, it was determined that wear resistance of anodized Ti45Nb alloy improved. In addition, the surface roughness and porosity of the material increased with increasing anodization potential.
\end{abstract}

Keywords: Anodizing, Wear, Niobium, Titanium, Ti45Nb

\footnotetext{
*aMuharrem TAŞDEMIR; mtasdemir1620@gmail.com, Tel (0456) 2331000 (dahili: 1615), orcid.org/0000-0003-3291-108X

${ }^{\mathrm{b}}$ orcid.org/0000-0003-0498-6332 $\quad{ }^{\mathrm{c}}$ orcid.org/0000-0002-8096-0794
} 


\section{Giriş}

Titanyum ve alaşımlarının başta havacılık ve uzay sanayi olmak üzere otomotiv, denizcilik, kimya endüstrisi ve biyomedikal alanlarda sergilediği yüksek özgül mukavemet, yüksek korozyon direnci ve iyi biyouyumluluk özelliklerinden dolayı kullanımı giderek artmaktadır (Bloyce, 1998, Habazaki, 2007). Titanyum ve alaşımlarının kimyasal kompozisyonunu, mekanik ve biyouyumluluk özelliklerini geliştirmek amacıyla çeşitli elementler katılmaktadır. Son yıllarda ticari titanyuma, niyobyum $(\mathrm{Nb})$ elementi katılmasıyla $\beta$ titanyum alaşımları geliştirilmişsir. $\beta$ titanyum alaşımları çok geniş kullanım alanına sahiptir (Godley, 2006). Bunlardan biri karşıllklı iki parçanın temasta olduğu kuru kayma şartını sağlayan triboloji alanıdır. Kuru kayma şartları aşınma oranı açısından en kötü aşınma durumudur. Titanyum alaşımlarının kuru kayma şartlarında yükün etkisiyle aşınma oranı önemli derecede artış göstermektedir (Zhao, 2018). Titanyumun zayıf tribolojik özellikleri literatürde iki temel faktör ile ifade edilmiştir. Birincisi adhezif ve abrazif tabakalı aşınma, ikincisi ise oksidatif aşınmadır. Yüzeydeki oksit tabakası yükün etkisiyle parçalanması ya da dökülmesi sonucu aşınmaya karşı yüzey altını koruyamamaktadır. Ayrıca atmosferden gelen çözünmüş oksijen, yapıyı gevrekleştirerek titanyumun aşınma dayanımını düşürmektedir (Hacisalioglu, 2017).

Titanyum ve alaşımlarının aşınma direncini ve kullanım süresini artırmak amacıyla çeşitli yüzey işlemleri uygulanmaktadır. Titanyum ve alaşımlarına uygulanan başlıca yüzey işlemleri; anodizasyon, oksijen difüzyon, iyon implantasyon, termal oksidasyon, fiziksel buhar biriktirme, kimyasal buhar biriktirme ve sol gel yöntemleri olarak siralanabilir (Krishna, 2007; Minagar, 2012). Titanyuma uygulanan yüzey işlemlerinde en s1k tercih edilen yöntem oksidasyon temelli yüzey işlemleridir. Taban malzeme titanyum esaslı olduğundan dolay1 yüzeyde oluşan yapı $\mathrm{TiO}_{2}$ 'dir. $\mathrm{TiO}_{2}$ fotokataliz, güneş hücreleri, gaz sensörleri, biyomedikal ve optik araçlarda kullanılır (Macak, 2007). Yüzey oksidasyon yöntemlerinden termal oksidasyon, anodizasyon, mikro ark oksidasyon, plazma elektrolit oksidasyon ile titanyumun yüzey özelliklerinin geliştirildiği çalışmalar literatürde yer almaktadır (Dong, 2000; Yetim, 2010; Çelik, 2014;Alsaran, 2011; Yavari, 2016). Bu yöntemler içerisinde kurulumunun kolay, üretim maliyetinin uygun olması ve düşük çalışma sıcaklıklarda gerçekleştirilebilmesi gibi avantajları nedeniyle anodizasyon işlemi bir adım öne çıkmaktadır (Dong, 2010). Titanyum anodizasyonun önemli bir diğer teknolojik avantajı ise havacılık endüstrisinde adhezyon ve bağlanmayı geliştirmesidir. Anodizasyon işlemi parametrelerinin değiştirilmesiyle titanyumun yüzeyindeki oksit tabakasının formu ve kalınlığ kontrol edilebilmektedir (Liu, 2004). Elektrolit konsantrasyonu ve sicaklığı, uygulanan akım yoğunluğu ve voltajı, karıştırma hızı, anot ve katot yüzey oranları malzemenin yüzeyindeki oksit tabakasının formu ve kalınlığını önemli ölçüde etkilemektedir (Kuromoto, 2007). Titanyum atmosfere bırakıldığında yüzeyinde 3-8 nm kalınlığında doğal oksit tabakası oluşmaktadır (Jang, 2009). Anodikoksidasyonda ise atmosferde doğal olarak oluşan oksit tabakasından daha yoğun ve kalın bir oksit tabakasının elde edilmesini imkân sağlamaktadır (Liu, 2004). Ti45Nb alaşımının yüksek basınç torsiyonu ve aşırı plastik deformasyon ile mekanik dayanımın artırıldı̆̆ 1 ayrıca anodizasyon prosesi ile yüzey özelliklerinin geliştirildiği çalışmalar literatürde mevcuttur (Völker, 2017;Panigrahi, 2016;Zorn, 2006). Fakat anodizasyon işleminin kuru aşınma şartlarına etkisi ile ilgili çalı̧̧ma literatürde bulunmamaktadır.

$\mathrm{Bu}$ çalışmada; Ti45Nb'un zayıf olan yüzey özelliklerini geliştirmek amacıyla anodizasyon işlemi uygulanmıştır. Ti45Nb'un yüzeyinde oluşan oksit film yapısının tribolojik özelliklere etkisi kuru aşınma şartları altında incelenmiştir.

\section{Materyel ve Yöntem}

\subsection{Deneysel Çalışmalar}

$\mathrm{Bu}$ çalışmada taban malzeme olarak $14 \times 14 \times 3$ $\mathrm{mm}^{3}$ ebatlarında Ti45Nb (Grade 36) prizmatik numuneler kullanılmıştır. Ti45Nb (Grade 36)'ın kimyasal kompozisyonu Tablo 1'de verilmiştir. Numune yüzeyleri 400-2000 grit aralığında aşamalı olarak Silisyum karbür (SiC) zımparalar kullanılarak parlatılmış ve ardından etanol ile yıkanarak kurutulmuştur. Anodizasyon işlemi 550 Watt $50 \sim 60 \mathrm{~Hz}$ doğru akıma sahip güç kaynağ 1 kullanılarak oda sıcaklığında $1.5 \mathrm{M} \mathrm{H}_{2} \mathrm{SO}_{4}$ (saflığ \%96) çözeltisi içerisinde $125 \mathrm{~V}, 175 \mathrm{~V}, 225 \mathrm{~V}$ sabit potansiyelde 10 dakika boyunca sürekli karıştırılarak gerçekleştirilmiştir. Kaplama prosesinde katot olarak paslanmaz çelik, anot olarak Ti45Nb numunesi kullanılmıştır. $125 \mathrm{~V}$, $175 \mathrm{~V}, \quad 225 \mathrm{~V}$ gerilim değerinde yapılan anodizasyon işleminde numuneler sırasıyla A125, A-175, A-225 olarak adlandırılmıştır. Numunelerin Vickers sertlik deneyi $980.7 \mathrm{mN}$ 
yük altında yapılmıştır. İşlemsiz ve anodize edilmiş numunelerin aşınma deneyi Turkyus marka aşınma test cihazı kullanılarak gerçekleştirilmiştir. Aşınma deney sistemine ait parametreler Tablo 2'de verilmiştir.

Tablo 1. Ti45Nb'in kimyasal kompozisyonu

\begin{tabular}{|l|l|l|l|l|l|l|}
\hline & $\mathrm{Nb}$ & $\mathrm{Ti}$ & $\mathrm{Fe}$ & $\mathrm{O}$ & $\mathrm{C}$ & Others \\
\hline ASTM B-348 & $42.0-47.0$ & Balance & $0.03(\max )$ & $0.16(\max )$ & $0.04(\max )$ & $0.04(\max )$ \\
\hline Ti45Nb & 45.11 & 54.69 & - & - & - & 0.20 \\
\hline
\end{tabular}

İşlemsiz ve anodik oksitleme işlemi yapılmış numunelerin faz analizleri XRD yardımı ile belirlenmiştir. XRD ölçümleri $\mathrm{Cu}-\mathrm{K} \alpha$ 1şınımı ve $1.54060 \AA$ dalga boyu kullanılarak $2 \theta^{\circ}=20-90^{\circ}$ tarama aralığında $2 \%$ dk tarama hızında gerçekleştirilmiştir. Numunelerin yüzey görüntüleri ve film kalınlığı SEM cihazı yardımı ile incelenmiştir. Aşınma deneyleri sonucunda oluşan yüzeyler Zeiss marka optik mikroskop ile görüntülenmiştir. Ayrıca aşınmış yüzeylerden 3Dprofilometre yardımı ile aşınma hacmi elde edilmiştir. Aşınma hacmi hesaplanması Archard aşınma kanununa göre aşağıda verilen (1) no'lu formüle göre belirlenmiştir (Archard, 1980). Bu eşitlikte yer alan V hacim kaybını, W uygulanan yükü, L kayma yolunu, $H$ malzemenin sertliğini ve $\mathrm{k}$ aşınma sabitini göstermektedir.

$V=\frac{k W L}{H}$

İşlemsiz ve anodize edilmiş numunelerin yüzey pürüzlülük değerleri MarSurf PS1 yüzey pürüzlülüğü cihazıyla ölçülmüştür. Sürtünme katsayıs1 Coulomb sürtünme kanununa göre aşağıda verilen (2) no'lu formüle göre hesaplanmıştır. Denklemde; FS sürtünme kuvveti, $F_{N}$ deney yükünü, $\mu$ sürtünme katsayısını tanımlamaktadır.

$\mu=\frac{F_{S}}{F_{N}}$

Tablo 2. Aşınma deney sistemine ait parametreler

\begin{tabular}{|l|l|}
\hline Parametreler & Değerler \\
\hline Deney yükü ve süresi & $2 \mathrm{~N} / 3000 \mathrm{~s}$ \\
\hline Aşındırıcı tipi ve çapı & $\mathrm{Al}_{2} \mathrm{O}_{3} / 6 \mathrm{~mm}$ \\
\hline Hareket tipi & Doğrusal zıt yönlü \\
\hline $\begin{array}{l}\text { Aşınma genliği ve } \\
\text { frekansı }\end{array}$ & $7 \mathrm{~mm} / 1 \mathrm{~Hz}$ \\
\hline Mesafe & $50.4 \mathrm{~m}$ \\
\hline
\end{tabular}

\section{Bulgular}

\subsection{Yaptsal Özellikler}

İşlemsiz ve farklı şartlarda anodize edilmiş Ti45Nb alaşımının XRD sonuçları Şekil 1'de verilmiştir. Bütün numunelerde bağıl olarak en yüksek yansıma piki $2 \theta^{\circ}=38^{\circ}$ 'de $\beta$-Ti'dur. A- 125 ve A-175 numunesinde $2 \theta^{\circ}=25^{\circ}$ 'de anataz titanyum oksit faz yapis1, A-225 numunesinde ise $2 \theta^{\circ}=25^{\circ}$ 'de anataz titanyum oksit faz yapisiyla birlikte $2 \theta^{\circ}=27^{\circ}$ ' de rutil titanyum oksit faz yapıs1 ortaya çıkmıştır. $2 \theta^{\circ}=25^{\circ}$ deki anataz fazının düzlemi (101) ve $2 \theta^{\circ}=27^{\circ}$ ' deki rutil faz yapısının düzlemi (110) şeklindedir (Han, 2018). Düşük gerilim değerlerinde yapılan anodizasyon işleminde titanyum oksit yapısında anataz fazı hâkimken, yüksek gerilim değerlerinde rutil faz yapıs1 hâkimdir. Anodizasyon potansiyelinin artmasiyla titanyumun oksit yapisinda rutil faz oranının arttığı görülmektedir. Bununla birlikte; işlemsiz Ti45Nb alaşımının $2 \theta^{\circ}=38^{\circ}, 56^{\circ}, 69^{\circ}, 83^{\circ}$ 'de $\quad \beta$-Ti pikleri elde edilmiştir. Martins vd. (2010)'nin yapmış oldukları bir çalışmada toz metalurjisi yöntemiyle ürettikleri Ti45 $\mathrm{Nb}$ alaşımının işlemsiz numunelerinden alınan XRD sonuçlarındaki pikler ile yapmış olduğumuz çalışmadaki pikler birbirine uyumludur. Ayrica, Zorn vd. (2006) $2 \theta^{\circ}=47^{\circ}$ ve $2 \theta^{\circ}=53^{\circ}$ anataz fazına ait piklerini ve $2 \theta^{\circ}=69^{\circ} \beta$ Ti pikini tespit etmişlerdir.

İşlemsiz ve farklı şartlarda anodize edilmiş Ti45Nb numunelerin yüzey görüntüsü Şekil 2'de gösterilmektedir. Anodizasyon işlemi sonrasında numunelerin yüzeyinde homojen $\mathrm{TiO}_{2}$ film katmanı elde edilmiştir. Anodizasyon potansiyelinin değişmesiyle malzemenin yüzeyinde farklı kalınlıklarda çeşitli oksit formları oluşmuştur. $\mathrm{Bu}$ durum uygulanan voltaj ve akım değerlerinin farkından kaynaklanmaktadır. Ayrıca artan anodizasyon geriliminin etkisiyle malzemenin yüzeyindeki kaplamanın rengi metalikten yeşilimsi renge dönüşmüştür. Nitekim Zorn vd. (2006) tarafindan yapılan bir çalışmada değişen gerilim değerlerinde malzemenin 
yüzeyinde farklı renklerde oksit formların meydana geldiğini rapor etmişlerdir. Şekil $2 b$ 'de A-125 prosesinde görüldüğü gibi malzeme yüzeyinde kanal şeklinde yapılar oluşmuştur. A175 prosesinde kanal şeklindeki yapılar düzenli porlara dönüşerek tüm yüzeyi kaplamıştır. Anodizasyon potansiyelinin artmasıyla porların sayısı önemli miktarda artmıştır. Bu durum Şekil 2c'de açıkça görülmektedir. Nitekim TiNb alaşımlarında $\mathrm{Nb}$ içeriğinin artmasıyla nanoporların çapları ve uzunluğunun arttığı Jang tarafindan gözlemlenmiştir (Jang, 2009). Anodizasyon potansiyelinin $225 \mathrm{~V}$ olmasiyla bu porlu yapılar yünsü yapıya dönüşmeye başlamıştır.

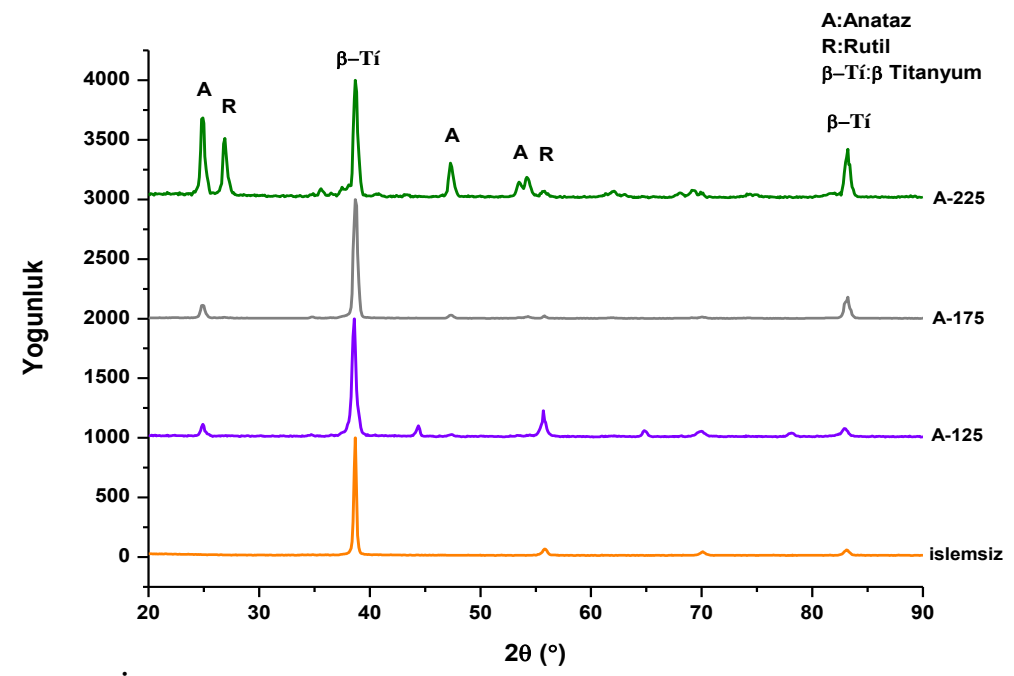

Şekil 1. İşlemsiz ve farklı şartlarda anodize edilmiş Ti45Nb alaşımının XRD Grafiği
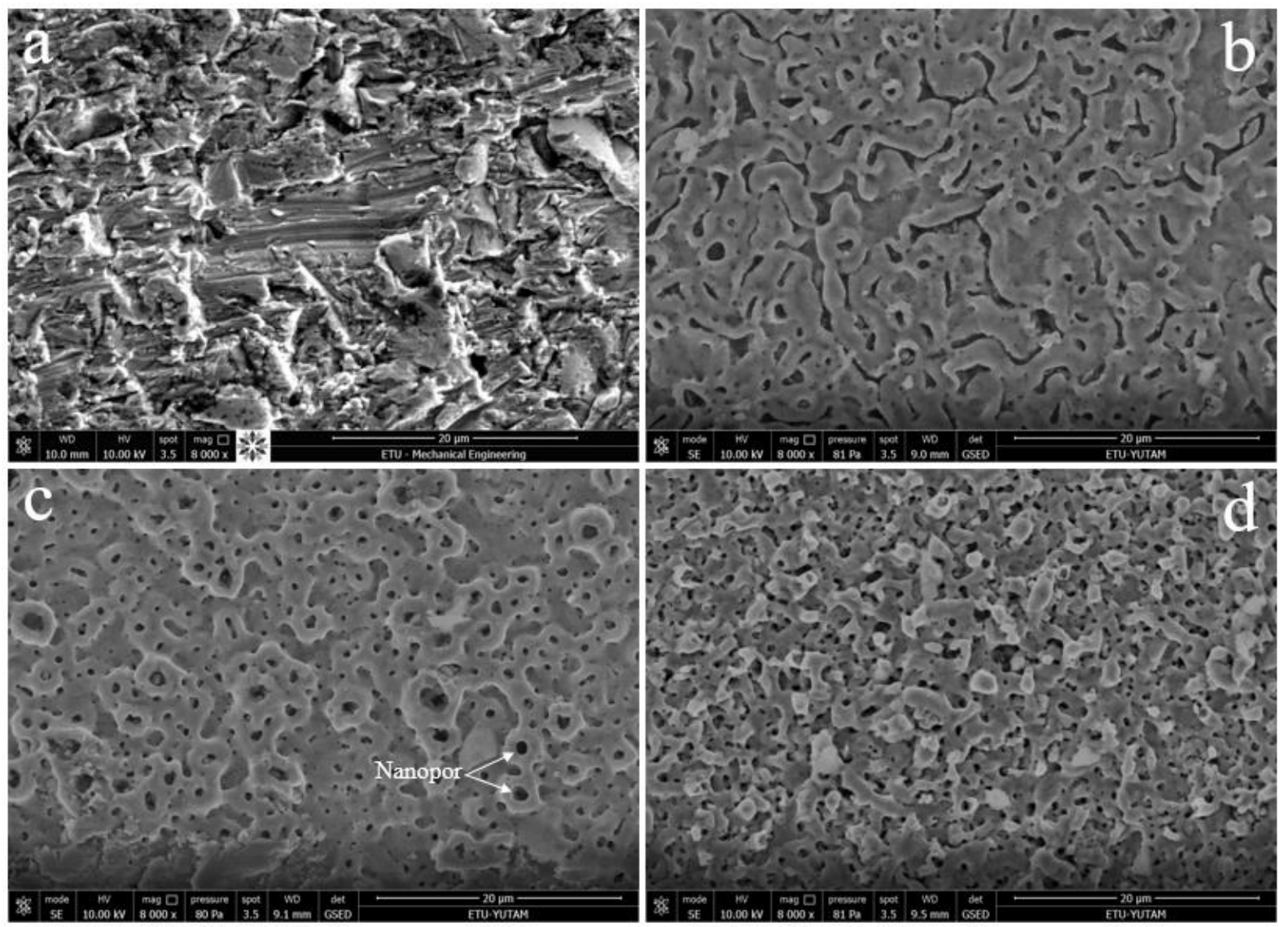

Şekil 2. İşlemsiz ve farklı şartlarda anodize edilmiş Ti45Nb alaşımlarının yüzey görüntüleri a) işlemsiz b) A-125 c) A-175 d) A-225 
Anodize edilmiş numunelerin kaplama kalınlığ kesit görüntülerinden belirlenmiştir. Bu bağlamda, $225 \mathrm{~V}$ gerilim değerinde anodize edilmiş Ti45Nb alaşımının kesit görüntüsünün SEM fotoğrafi Şekil 3'de verilmiştir. A-125 numunesinin kaplama kalınlığ1 $1.5 \pm 0.3 \quad \mu \mathrm{m}, \quad \mathrm{A}-175$ numunesinin kaplama kalınlığ $5 \pm 0.5 \mu \mathrm{m}, \mathrm{A}-225$ numunesinin kaplama kalınlığ $11 \pm 0.7 \mu \mathrm{m}$ 'dir. Kesit görüntülerinden elde edilen sonuçlara göre anodizasyon potansiyelinin artmasıyla birlikte titanyumun yüzeyindeki kaplama kalınlığının $\operatorname{arttığ}_{1}$ tespit edilmiştir. Bununla beraber anodizasyon potansiyelinin artması ile daha kısa sürelerde daha fazla kaplama kalınlığ 1 elde edilebilir. Ancak hızla artan kaplama kalınlığı oluşan arkların etkisiyle homojen ve kararlı olamamaktadır. $\mathrm{Bu}$ durum filmin taban malzemeye yeterli adhezyon sağlayamamasına neden olabilir. $\mathrm{Bu}$ nedenler kaplama kalitesini olumsuz yönde etkileyeceği düşünülmektedir.

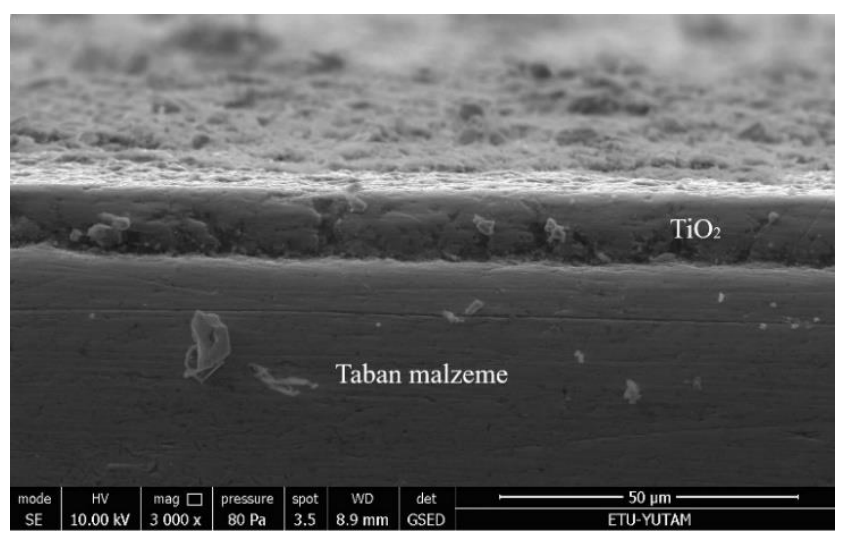

Şekil 3. A-225 numunesinin kaplama kesit görüntüsünün SEM fotoğrafı

İşlemsiz ve farklı şartlarda anodize edilmiş numunelerin yüzey sertliği ve pürüzlülük değerleri Tablo 3'de gösterilmektedir. $\mathrm{Bu}$ tablodan anodizasyon işlemi görmüş numunelerin yüzey sertliği ve pürüzlülük değerlerinin arttığ görülmektedir. En düşük yüzey sertliği ve pürüzlülük değeri sirasıyla $220 \pm 20 \quad \mathrm{HV}_{0.1}$ ve $0.20 \pm 0.1 \mu \mathrm{m}$ ile işlemsiz Ti45Nb numunesinde elde edilmiştir. En yüksek yüzey sertliği ve pürüzlülük değeri ise sirasıyla $845 \pm 56 \mathrm{HV}_{0.1}$ ve $0.48 \pm 0.1 \mu \mathrm{m}$ ile A-225 numunesinden elde edilmiştir. Anodizasyon işleminden sonra malzemenin yüzeyinde gerilimin etkisiyle oluşan ark numunelerin yüzey pürüzlülüğünü artırmıştır. Zorn vd. (2005)'de yapmış olduğu çalışmada; Ti45Nb'un anodizasyon potansiyelininin artmasıyla malzemenin yüzey pürüzlülüğünün arttığını gözlemlemişlerdir. Kim vd. (2013)'de yapmış olduğu çalışmada; anodizasyon yöntemi ticari titanyumun yüzey pürüzlülügünü artırmada etkili olduğunu ifade etmişlerdir.

Tablo 3. İşlemsiz ve farklı şartlarda anodize edilmiş Ti45Nb alaşımlarının yüzey sertliği ve pürüzlülük değerleri

\begin{tabular}{|l|l|l|l|l|}
\hline Malzeme & Ti45Nb & A-125 & A-175 & A-225 \\
\hline Yüzey Sertliği $\mathrm{HV}_{0.1}$ & $220 \pm 20$ & $323 \pm 58$ & $654 \pm 49$ & $845 \pm 56$ \\
\hline Yüzey Pürüzlülüğ̈̈ $(\mu \mathrm{m})$ & $0.20 \pm 0.1$ & $0.37 \pm 0.1$ & $0.44 \pm 0.1$ & $0.48 \pm 0.1$ \\
\hline
\end{tabular}

\subsection{Tribolojik Özellikler}

İşlemsiz ve farklı şartlarda anodize edilmiş Ti45 $\mathrm{Nb}$ numunelerin sürtünme katsayısı-zaman eğrisi grafikleri Şekil 4'de gösterilmiştir. İşlemsiz $\mathrm{Ti} 45 \mathrm{Nb}$ numunenin sürtünme katsayısı-zaman grafiğinden, sürtünme katsayısı değerinin deney sonuna kadar artarak devam ettiği görülmektedir. İşlemsiz numunede sürtünme katsayısının sürekli artmasının sebebi; aşınma davranışına ve temas yüzeylerinin durumuna dayandırılarak açıklanabilir. Şöyle ki, işlemsiz numunede adhezif aşınma sonucunda kazınan parçacıkların bir kısmının aşınma yüzeylerine yeniden birikmesi, kayma esnasında harekete karşı bir direnç oluşturmaktadır. Diğer bir ifadeyle aşınma esnasinda oluşan deformasyon ve adhezif birleşmenin dayanımı sürtünme katsayısının artmasına neden olmuştur. Ayrıca işlemsiz numunenin yüzey sertliğinin, anodize edilmiş 
numunelerinkine göre daha düşük olması aşınma iz genişliğini önemli ölçüde artırmıştır. Bu durum aşınma yüzeyleri arasındaki temas alanını artırdığından dolayı sürtünme katsayısının artmasına neden olmuştur. İşlemsiz numunenin adhezif etkisi Şekil 6a ve Şekil 6c'deki aşınma izlerinden görülmektedir. Şekil 4b'de A-125 numunesinde testin başlangıcında sürtünme katsayısının artış eğilimi Hertz kontak basıncından kaynaklanmaktadır. A-175 ve A-225 numunelerin sürtünme katsayı değerleri kayma durma etkilerinden dolayı dalgalı seyir göstermiştir. En yüksek ortalama sürtünme katsayısı değeri düşük yüzey sertliğinden dolayı işlemsiz Ti45Nb alaşımında elde edilmiştir.

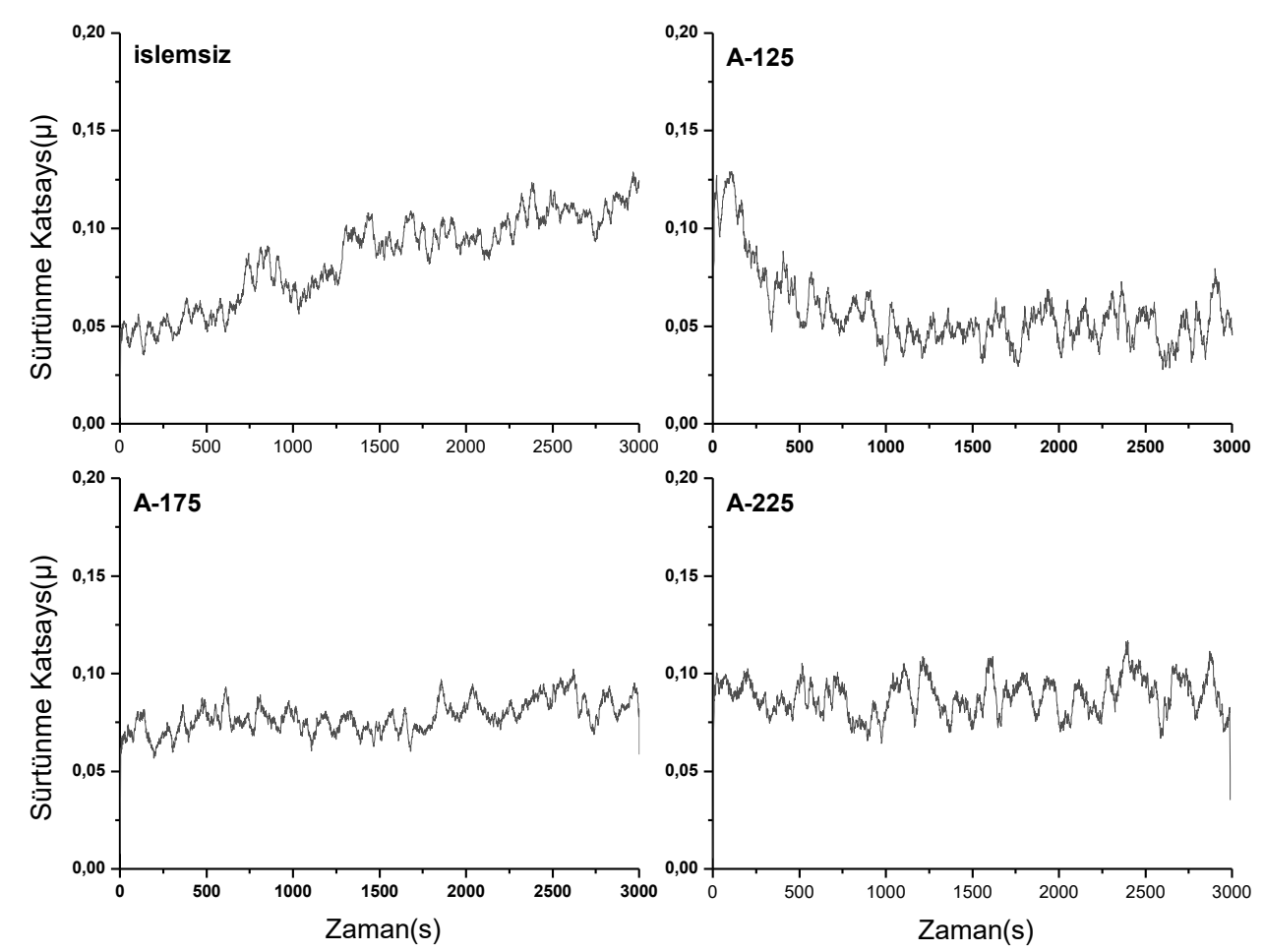

Şekil 4. İşlemsiz ve farklı şartlarda anodize edilmiş Ti45Nb alaşımlarının sürtünme katsayısı grafikleri

İşlemsiz ve farklı şartlarda anodize edilmiş $\mathrm{Ti} 45 \mathrm{Nb}$ numunelerin aşınma hacmi miktarları ve A-175 koşulunun 3D profilometre yüzey görüntüsü Şekil 5'de verilmiştir. A-175 ve A-225 numunelerinin aşınma dayanımı işlemsiz alaşıma göre arttığı Şekil 5a'daki aşınma hacmi grafiğinde açıkça görülmektedir. Anodize edilmiş Ti45Nb alaşımlarının aşınma dayanımlarının artmasının sebebi yüzeyde bulunan anataz ve rutil titanyum oksit tabakasının yüzey sertliğini ve dayanımını artırmasından kaynaklanmaktadır. Ancak yapılan çalışmada A-125 koşulundaki Ti45Nb alaşımı işlemsiz numune gibi davranış göstermiştir. Bu durum koruyucu yüzey tabakası olan titanyum oksit tabakasının yetersiz film kalınlığından kaynaklanmıştır. Aynı zamanda aşınmanın erken safhalarında yüzeyden kazınan oksit tabakası bu duruma neden olmuştur. Şekil 5b'de A-175 koşulunun 3D profilometre yüzey görüntüsü verilmiştir. A-175 numunesinde aşınma bölgesinin ortasında yüzey gerilmelerinden dolayı kaplamanın kalktığ 1 , aşınma kenarlarında aşınma izlerinin azaldığı görülmektedir. Han vd. (2018)'de yapmış olduğu çalışmada; anodizasyon prosesi ile titanyum-vanadyum alaşımın aşınma dayanımının geliştirdiğini belirtmişlerdir.

İşlemsiz ve A-225 koşulunda anodize edilmiş $\mathrm{Ti} 45 \mathrm{Nb}$ alaşımının aşınma sonrası genel ve detay yüzey görüntüleri Şekil 6'da verilmiştir. Şekil 6.ab'de işlemsiz ve A-225 numunesinin aşınma izleri karşılaştırıldığında, A-225 numunesinin aşınma iz genişliği ve iz derinliği işlemsiz numuneye göre oldukça daralmış ve azalmış olduğu görülmektedir. Şekil $6 c^{\prime}$ de ise işlemsiz Ti45Nb numunesinin detay resminden aşınma mekanizmasının adhezif etkiyle kazıma şeklinde gerçekleştiği anlaşılmaktadır. Şekil 6d'de A-225 numunesinde aşınma yükünün etkisiyle kaplama tabakasının malzeme yüzeyinden bölgesel koparak ayrıldığı görülmektedir. A-225 numunesinin aşınma testleri sonucunda, aşındırıcı 
ucun taban malzemeye inemediği, kaplama tabakasının ise koruyucu etkisini kaybetmediği tespit edilmiştir. Anodize edilmiş numunelerin işlemsiz numuneye göre daha üstün aşınma direnci sergilemesi bunların işlemsiz numuneye göre daha yüksek yüzey sertliğine sahip olmasından kaynaklanmaktadır. Artan yüzey sertliği anodize edilmiş numunelerin plastik deformasyona karşı dirençlerini artırarak temas alanının azalmasına dolayısıyla aşınma dirençlerinin artmasına neden olmuştur. Nitekim en yüksek yüzey sertliğine sahip olan A-225 numunesi aynı zamanda en düşük aşınma hacmine sahiptir. Diğer bir ifadeyle en iyi aşınma direnci A-225 numunesine aittir.
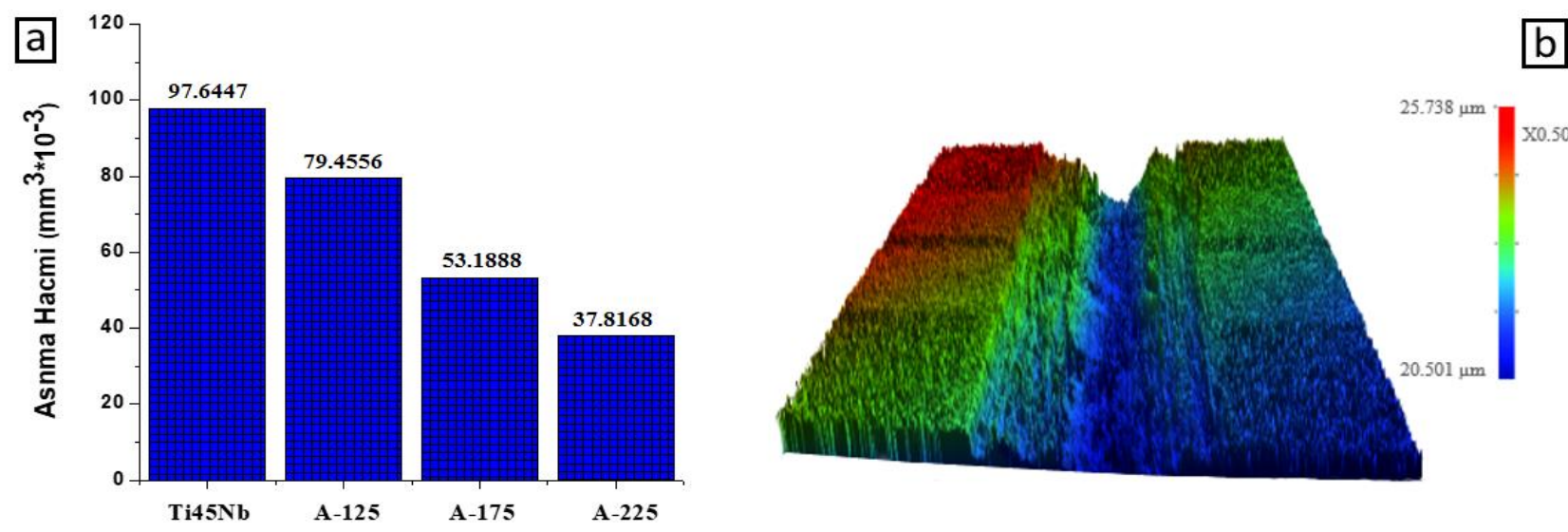

Şekil 5. İşlemsiz ve farklı şartlarda anodize edilmiş Ti45Nb alaşımlarının aşınma hacmi grafikleri ve b) A175 koşulunun 3D profilometre yüzey görüntüsü
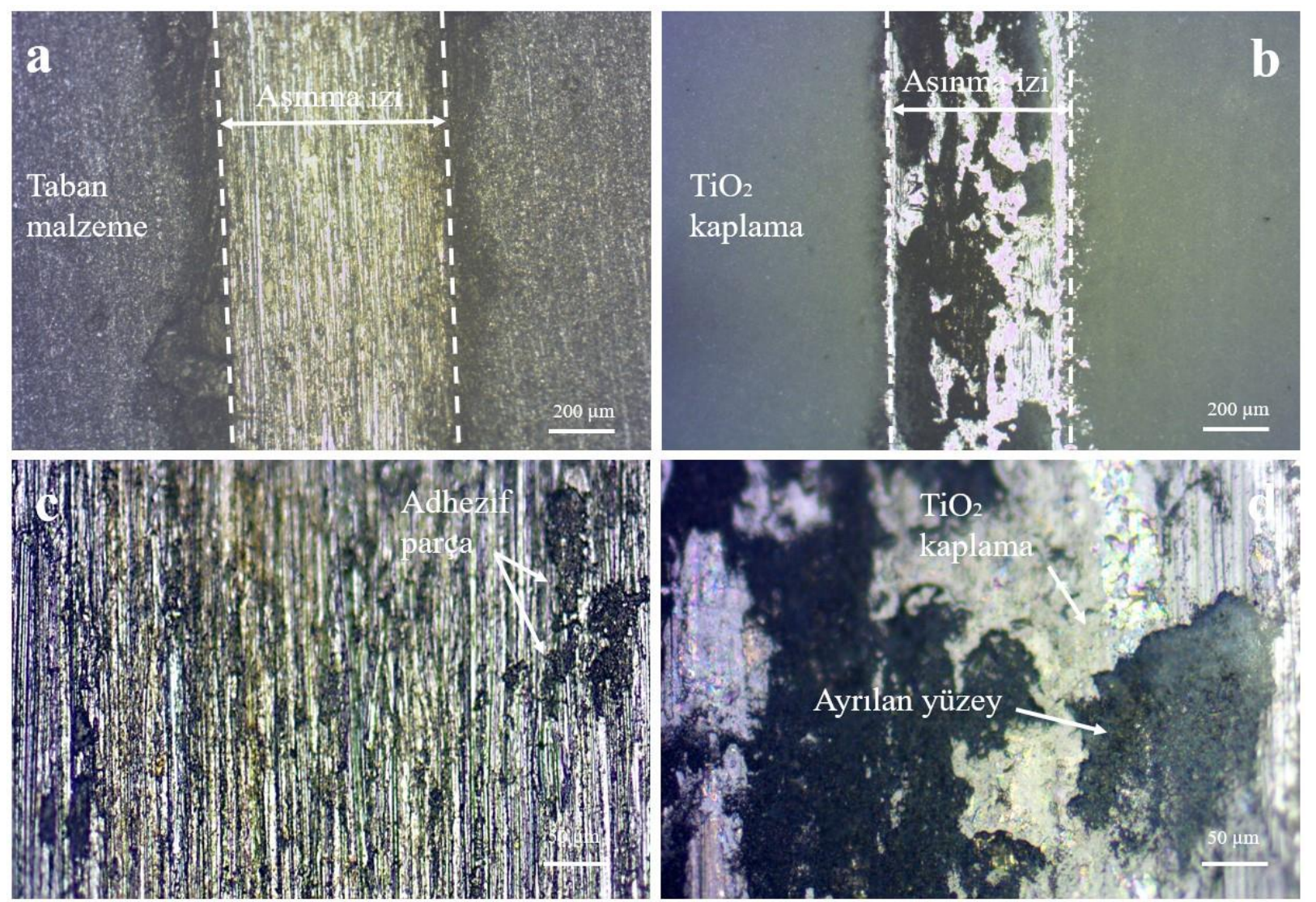

Şekil 6. Ti45Nb alaşımının aşınma sonrası yüzey görüntüleri a) işlemsiz b) A-225 c) işlemsiz detay resmi d) A-225 detay resmi 


\section{Sonuçlar}

$\mathrm{Ti} 45 \mathrm{Nb}$ alaşımının aşınma davranışına anodizasyon potansiyelinin etkisi deneysel olarak incelenmiştir. Elde edilen sonuçlar aşağıda verilmiştir.

- Anodizasyon potansiyelinin değiştirilmesiyle Ti45Nb alaşımının yüzeyinde titanyum oksit yapısının formu ve kalınlığı kontrol edilebilmektedir.

- Anodizasyon potansiyelinin artmasiyla Ti45Nb alaşımının yüzeyindeki titanyum oksit film tabakasının kalınlığı arttığı belirlenmiștir. En yüksek oksit film tabaka kalınlığ $11 \mu \mathrm{m}$ ile A225 numunesinde elde edilmiştir.

- Anodizasyon işlemi Ti45Nb alaşımının yüzey pürüzlülügünü arttırdığ 1 tespit edilmiştir.

- Anodizasyon potansiyelinin artmasiyla Ti45Nb alaşımının yüzey sertliği artmış; buna bağlı olarak da malzemenin aşınma dayanımı oldukça gelişmiştir.

- Anodize edilmiş numunelerin sürtünme katsayısı değerleri işlemsiz numuneye göre oldukça azaldığı belirlenmiştir.

\section{Kaynaklar}

Alsaran, A., Purcek, G., Hacisalihoglu, I., Vangolu, Y., Bayrak, Ö., Karaman, I. ve Celik, A., 2011. Hydroxyapatite Production On UltrafineGrained Pure Titanium By Micro-Arc Oxidation And Hydrothermal Treatment. Surface and Coatings Technology, 205, 537-542.

Archard, J.F., 1980. Wear Theory and Mechanisms. New York, NY, ASME. New York, NY.

Bloyce, A., Qi, P. Y., Dong, H., ve Bell, T., 1998. Surface Modification Of Titanium Alloys For Combined Improvements In Corrosion And Wear Resistance. Surface and Coatings Technology, 107(2-3), 125-132.

Çelik, İ., Alsaran, A., ve Purcek, G., 2014. Effect Of Different Surface Oxidation Treatments On Structural, Mechanical And Tribological Properties Of Ultrafine-Grained Titanium. Surface and Coatings Technology, 258, 842848.

Dong, H., 2010. Surface Engineering of Light Alloys Aluminium, Magnesium, Titanium Alloys, Woodhead Publishing Limited.

Dong, H. ve Bell, T., 2000. Enhanced Wear Resistance Of Titanium Surfaces By A New Thermal Oxidation Treatment. Wear. 238, 131-137.

Godley, R., Starosvetsky, D., ve Gotman, I., 2006. Corrosion Behavior Of A Low Modulus B-Ti-
$45 \% \mathrm{Nb}$ Alloy For Use In Medical Implants. Journal of Materials Science: Materials in Medicine, 17(1), 63-67.

Habazaki, H., Onodera, T., Fushima, K., Konno, H., ve Toyotake, K., 2007. Spark Anodizing Of B-Ti Alloy For Wear-Resistant Coating. Surface and Coatings Technology, 201(21), 8730-8737.

Hacisalioglu, I., Yildiz, F., Alsaran, A., ve Purcek, G., 2017, February. Wear Behavior Of The Plasma And Thermal Oxidized Ti-15Mo And Ti-6Al4V Alloys. In IOP Conference Series: Materials Science and Engineering (Vol. 174, No. 1, p. 012055). IOP Publishing.

Han, B., Zal Nezhad, E., Musharavati, F., Jaber, F., ve Bae, S., 2018. Tribo-Mechanical Properties And Corrosion Behavior Investigation of Anodized Ti-V Alloy. Coatings, 8(12), 459.

Jang, S. H., Choe, H. C., Ko, Y. M., ve Brantley, W. A., 2009. Electrochemical Characteristics Of Nanotubes Formed On Ti-Nb Alloys. Thin Solid Films, 517(17), 5038-5043.

Kim, K., Lee, B. A., Piao, X. H., Chung, H. J., ve Kim, Y. J., 2013. Surface Characteristics And Bioactivity Of An Anodized Titanium Surface. Journal of periodontal \& implant science, 43(4), 198-205.

Krishna, D.S.R. Brama, Y.L. ve Sun, Y., 2007. Thick Rutile Layer On Titanium For Tribological Applications. Tribology International, 40 (2), 329-334.

Kuromoto, N. K., Simao, R. A. ve Soares, G. A., 2007. Titanium Oxide Films Produced On Commercially Pure Titanium By Anodic Oxidation With Different Voltages. Materials Characterization, 58(2), 114-121.

Liu, X., Chu, P. K. ve Ding, C., 2004. Surface Modification Of Titanium, Titanium Alloys, And Related Materials For Biomedical Applications. Materials Science \& Engineering R-Reports, 47, 49-121.

Macak, J. M., Tsuchiya, H., Ghicov, A., Yasuda, K., Hahn, R., Bauer, S., ve Schmuki, P., 2007. TiO2 Nanotubes: Self-Organized Electrochemical Formation, Properties And Applications. Current Opinion in Solid State and Materials Science, 11(1-2), 3-18.

Martins, G. V.,Silva, C. R. M., Nunes, C. A., TravaAiroldi, V. J., Borges, L. A., ve Machado, J. P. B., 2010. Beta Ti-45Nb and Ti-50Nb Alloys Produced By Powder Metallurgy For Aerospace Application. In Materials Science Forum (Vol. 660, pp. 405-409). Trans Tech Publications. 
Minagar, S., Berndt, C.C., Wang, J., Ivanova, E., ve Wen, C., 2012. A Review Of The Application Of Anodization For The Fabrication Of Nanotubes On Metal Implant Surfaces.Acta Biomaterialia, 8(8), 2875-2888.

Panigrahi, A., Sulkowski, B., Waitz, T., Ozaltin, K., Chrominski, W., Pukenas, A., ... ve Zehetbauer, M., 2016. Mechanical Properties, Structural And Texture Evolution Of Biocompatible Ti$45 \mathrm{Nb}$ Alloy Processed By Severe Plastic Deformation. Journal of the mechanical behavior of biomedical materials, 62, 93-105.

Völker, B.,Jäger, N., Calin, M., Zehetbauer, M., Eckert, J., ve Hohenwarter, A., 2017. Influence Of Testing Orientation On Mechanical Properties Of Ti45Nb Deformed By High Pressure Torsion. Materials \& Design, 114, 4046.

Yavari, S. A., Necula, B. S., Fratila-Apachitei, L. E., Duszczyk, J., ve Apachitei, I., 2016. Biofunctional Surfaces By Plasma Electrolytic
Oxidation On Titanium Biomedical Alloys. Surface Engineering, 32(6), 411-417.

Yetim, A. F., 2010. Investigation Of Wear Behavior Of Titanium Oxide Films, Produced By Anodic Oxidation, On Commercially Pure Titanium In Vacuum Conditions. Surface and Coatings Technology, 205(6), 1757-1763.

Zhao, X., Xue, G., ve Liu, Y., 2017. Dry Sliding Tribological Behavior of TC11 Titanium Alloy Subjected to the Ultrasonic Impacting and Rolling Process. Metals, 8(1), 13.

Zorn, G., Gotman, I., Gutmanas, E. Y., Adadi, R., Salitra, G. ve Sukenik, C. N., 2005. Surface Modification of $\mathrm{Ti} 45 \mathrm{Nb}$ Alloy with an Alkylphosphonic Acid Self Assembled Monolayer. Chemistry of Materials. 17, 42184226.

Zorn, G., Lesman, A. ve Gotman, I., 2006. Oxide Formation On Low Modulus Ti45Nb Alloy By Anodic Versus Thermal Oxidation. Surface \& Coatings Technology, 201, 612-618. 